\section{Endoscopic Papillary Balloon Dilation in the Management of Common Bile Duct Stones in Patients with Roux-En-Y Reconstruction}

Endoscopic retrograde cholangiopancreatography and endoscopic transpapillary management of bile duct stones is more difficult in patients with a Roux-en-Y anastomosis than it is in patients with BillrothIIreconstructionsbecauseofdifferences in the postoperative anatomy. Two patients, a 48-year-old man (patient 1) and a 74-year-old man (patient 2), who had both undergone a total gastrectomy and Rouxen-Y anastomosis for gastric carcinoma, were admitted to our hospital for endoscopic treatment of common bile duct (CBD) stones. In both cases, a pediatric colonoscope (PCF-230; Olympus, Tokyo, Japan) was inserted into the RouX-en-Y limb up to the papilla. Endoscopic retrograde cholangiography revealed CBD stones with diameters of less than $10 \mathrm{~mm}$. Neither conventional sphincterotomes nor needle-knives could be safely positioned to perform endoscopic sphincterotomy (ES) in these patients. We therefore attempted to demonstrate that endoscopic papillary balloon dilation (EPBD) could be used as an alternative to ES. A balloon dilator (Max-Force Balloon Dilator; Microvasive, Boston Scientific Corporation, Water-

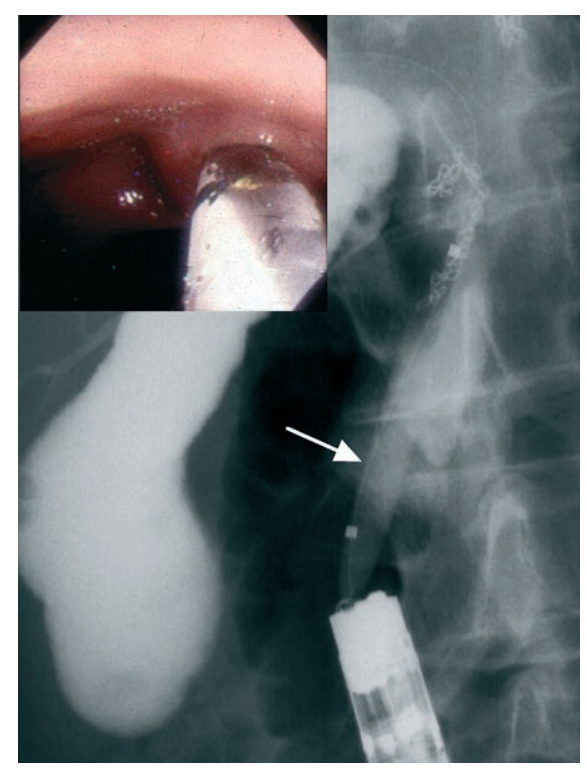

Figure 1 Endoscopic papillary balloon dilation in a 48-year-old man (patient 1) who had undergone a total gastrectomy and Roux-en-Y anastomosis. The cholangiogram shows the inflated balloon dilator (arrow) and the inset shows the endoscopic view. town, USA) was passed over the guide wire and into the common bile duct. The balloon was inflated to a diameter of $8 \mathrm{~mm}$ and a pressure of 3 atmospheres for $1 \mathrm{~min}$ ute (Figure 1). After EPBD, the stones were successfully extracted in both cases using a conventional basket catheter in a single procedure (Figure $\mathbf{2}$ ). There were no major complications. Although several techniques are available for performing ES in patients who have previously undergone Roux-en-Y anastomosis [1-3], it is not easy to maneuver the sphincterotome through a forward-viewing endoscope that has a long working length, such as the pediatric colonoscope. Compared with ES, the technical advantage of EPBD is the ease with which the opening of the bile duct can be enlarged without the need for fine control of the sphincterotome and endoscope. For this reason, EPBD has already been applied in endoscopic explorations for bile duct stones in patients who have had a Billroth II gastrectomy [4, 5]. In conclusion, EPBD appears to be particularly useful for managing bile duct stones in patients who have had a Rouxen-Y reconstruction.

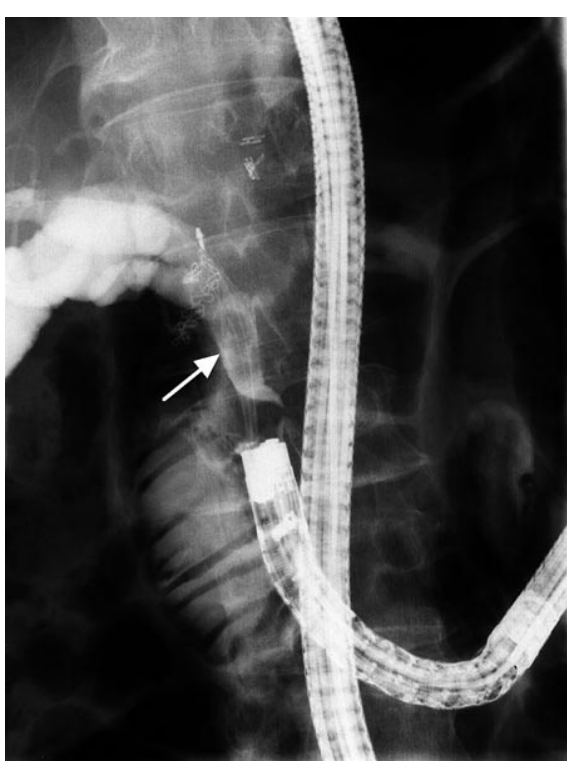

Figure 2 Fluoroscopic view of stone extraction using a conventional basket catheter after endoscopic papillary balloon dilation in patient 1 . The arrow points to the common bile duct stones caught in the basket catheter.
M. Inomata, M. Endo, H. Obara,

Y. Hashimoto, T. Terui, S. Oana,

N. Kudara, T. Chiba, S. Orii, K. Suzuki

First Department of Internal Medicine, Iwate Medical University School of Medicine, Iwate, Japan.

\section{References}

Elton E, Hanson BL, Qaseen T, Howell DA. Diagnostic and therapeutic ERCP using an enteroscope and pediatric colonoscope in long-limb surgical bypass patients. Gastrointest Endsc 1998; 47: 62-67

${ }^{2}$ Gostout CJ, Bender CE. Cholangiopancreatography, sphincterotomy, and common duct stone removal via Rouxen-Y limb enteroscopy. Gastroenterology 1988; 95: 156-163

${ }^{3}$ Hintze RE, Adler A, Veltzke W, Abou-Rebyeh $H$. Endoscopic sphincterotomy using an S-shaped sphincterotome in patients with a Billroth II or Roux-en-Y gastrojejunostomy. Endoscopy 1997; 29: $74-78$

${ }^{4}$ Tibble JA, Cairns SR. Endoscopic balloon sphincteroplasty: use in a patient with a Billroth II gastrectomy. Endoscopy 1996; 28: 790

${ }^{5}$ Bergman JJ, van Berkel AM, Bruno MJet al. A randomized trial of endoscopic balloon dilation and endoscopic sphincterotomy for removal of bile duct stones in patients with a prior Billroth II gastrectomy. Gastrointest Endosc 2001; 53: $19-26$

\section{Corresponding Author}

\section{Inomata, MD}

First Department of Internal Medicine Iwate Medical University School of Medicine

\section{9-1 Uchimaru}

Morioka

Iwate

Iwate 020-8505

Japan

Fax: +81-019-6526664

E-mail: minomata@iwate-med.ac.jp 